\title{
Tecendo redes em pesquisa operacional: experiência da enfermagem
}

Jordana de Almeida Nogueira ${ }^{1}$, Tereza Cristina Scatena Villa ${ }^{2}$, Aline Aparecida Monroe ${ }^{3}$

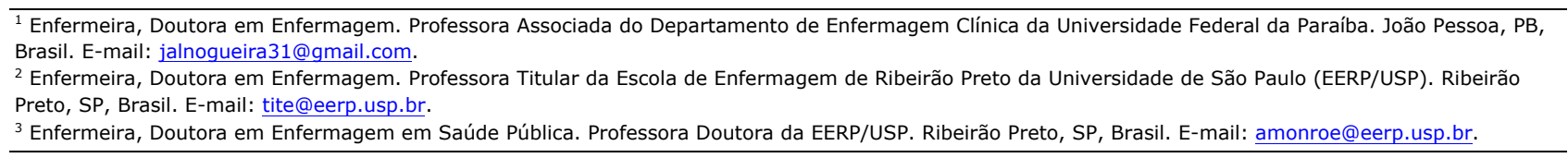

Se nas últimas décadas grandes mudanças ocorreram na forma de se comunicar, não seria diferente repensar e/ou redesenhar as estruturas que moldam as pesquisas científicas. A emergência de iniciativas multilaterais, ágeis, de amplo alcance, ganharam destaque inter e nacionalmente na perspectiva da "Pesquisa em Rede". Decisivamente é preciso renovar, ou melhor, inovar. Mas, porque integrar uma rede de pesquisa? Quais as contribuições da pesquisa em rede para Enfermagem?

Para respondermos a estas questões, entre outros elementos, é necessário inicialmente tecer algumas reflexões acerca do que se entende por pesquisa em rede. Partindo de sua gênese, a mesma se estabelece a partir de um sistema de conexões, cujos pontos integram e articulam pessoas, instituições e tecnologias ${ }^{(1)}$. Quando falamos em "conexões" nos reportamos a um processo dinâmico, mobilizado por "pessoas-ideias", sustentado por objetivos comuns. Sua identidade é definida por relações cotidianas de interesses, pela intensidade e persistência dos fluxos de comunicação entre os participantes.

Podemos dizer que esta rede de conversação, potencializa a horizontalidade das relações, valoriza a intencionalidade dos indivíduos com respeito às diferenças e à diversidade, aciona a corresponsabilidade e a colaboração, considera a realidade social concreta em que cada um se encontra ${ }^{(1)}$. Parece-nos que o exercício do trabalho em rede des(aprisiona) o pesquisador dos interesses focalizados, sem contudo distanciá-lo das premências locais. Na prática, viabiliza culturalmente o intercâmbio intelectual em torno de temáticas semelhantes, dinamiza as competências das unidades envolvidas e propicia maior agilidade na construção do conhecimento.

Tais características não nos deixa dúvida da importância de integrar uma rede de pesquisa. A intercomunicação com pares, o trabalho em equipe, a disseminação de propostas e achados de investigação(2), oportuniza romper paradigmas de trabalho alienados/alienantes. Contudo, não obstante aos aspectos positivos apontados, cabe destacar que manter orquestradamente e afinada a disposição dos integrantes da rede, não é uma tarefa fácil. Requer senso de coletividade, pactuações de agendas, elaboração de protocolos, cumprimento de prazos e compromissos. Pressupõe a existência de uma liderança encorajadora, capaz de nutrir a rede, negociar conflitos, reconhecer e incorporar novas ideias, incentivar uma cultura de aprendizagem e criar condição de empoderamento coletivo ${ }^{(1)}$. Ao valorizar a autonomia dos diferentes pontos que constituem a rede, fomenta o protagonismo de outras lideranças e grupos de pesquisa, que ao conectar-se com outros pontos, vão constituindo uma malha de relações ilimitada.

Na perspectiva da Enfermagem, entre outras iniciativas, focalizamos a experiência do Grupo Interinstitucional de Pesquisa Epidemiológica-Operacional em Tuberculose- GEOTB, que integra a Rede Brasileira de Pesquisa em Tuberculose- REDE TB. Liderado por um pesquisador da Enfermagem, desempenha papel importante na formação de novos pesquisadores em âmbito internacional, nacional e local, promove interlocução com diferentes Instituições de Ensino Superior, Serviços de Saúde e integra Comitês de Agências internacionais.

Num processo sistêmico e planejado, o GEOTB vem se consolidando no desenvolvimento de pesquisas de avaliação de serviços de saúde, considerando as modalidades de atenção, as tecnologias e gestão do cuidado para o controle da tuberculose ${ }^{(3)}$, incorporando, mais recentemente, o manejo de condições de saúde que possuem interface com o agravo, como o HIV/aids. Na atualidade, agrega pesquisadores de oito estados brasileiros, envolvendo docentes, discentes de graduação, mestrado, doutorado, profissionais e gestores dos serviços de saúde.

Tendo como foco o fortalecimento da formação, produção do conhecimento e transformação das práticas, destacamos como potencialidade, o compromisso com a interdisciplinaridade, ao facilitar a incorporação de profissionais de diversos campos do saber. Esta inclusão, tem permitido ampliar a composição dos referencias 
teóricos, avanços na qualidade metodológica e analítica, proporcionando know how aos pesquisadores para construção de projetos robustos e competência para captação de recursos financeiros.

Outro ponto que nos parece vital diz respeito a consolidação dos grupos emergentes. Na pesquisa em rede, 0 diálogo permanente com grupos de referência temática propicia aos pesquisadores menos experientes, interlocuções com outros cenários de pesquisa, aproximação à abordagens metodológicas distintas e/ou complementares, desenvolvimento de habilidades para manejo de tecnologias informacionais. Cria um sentido comum para a ação a partir da elaboração conjunta dos objetivos, regras e planos para a atuação.

Como efeitos desta interface, os grupos "periféricos" vão criando identidades e dinâmicas próprias, relações laterais, constituindo-se em um ponto de irradiação de novas conexões da rede, o que cria diversas oportunidades.

Por sua vez, os produtos gerados pelas pesquisas, oriundos de teses de doutorado, dissertações de mestrado e trabalhos de conclusão de curso, consolidam a produção da rede. O conhecimento produzido vem sendo amplamente divulgado em eventos científicos, publicados em periódicos nacionais e internacionais, principalmente nas áreas da Enfermagem e Saúde Pública, como também em boletins informativos, com maior acessibilidade para os trabalhadores de saúde.

As informações geradas no contexto da rede retroalimentam os grupos de pesquisa e se constituem objeto de reflexão para renovação das emergências. Embora tenhamos o compromisso de construir projetos em parceria com profissionais que atuam no campo da prática e da gestão, ainda é um grande desafio a transferência do conhecimento produzido e sua incorporação na prática social.

\section{REFERÊNCIAS}

1. Instituto Observatório Social [Internet]. São Paulo: Instituto Observatório Social (BR); 2007 [acesso em: 30 set. 2014 ]. Amaral V. Amaral V. Rede: uma abordagem operativa. Disponível em:

http://www.observatoriosocial.org.br/arqmorto/peas/arquivos/Redes_abordagem_Operativa.pdf.

2. Gatti BA. Formação de grupos e redes de intercâmbio em pesquisa educacional: dialogia e qualidade. Rev Bras Educ Med [Internet]. 2005 [acesso em: 30 set 2014];(30):124-32. Disponível em: http://dx.doi.org/10.1590/S1413-24782005000300010.

3. Villa TCS. Research strategies for controlling neglected diseases: collaborative network projects in nursing. Rev Lat Am Enfermagem [Internet]. 2009 [acesso em: 30 set 2014];17(4):439-40. Disponível em: http://dx.doi.org/10.1590/S0104-11692009000400001. 